\title{
TURISMO DE BASE COMUNITÁRIA E CULTURA ALIMENTAR: UM ESTUDO DE CASO NO LITORAL DO PARANÁ
}

\author{
Beatriz Leite Ferreira Cabral \\ Universidade Federal do Paraná (UFPR), Brasil \\ beatriz.cabral.ufpr@gmail.com \\ Dirson Teixeira Junior \\ Universidade Federal do Paraná (UFPR), Brasil \\ personalchef.dirson@gmail.com
}

Community based tourism, cuisine and food culture: a case study in the coast of Paraná

Turismo comunitario, cocina y cultura alimentaria: un estudio de caso en la costa de Paraná

DOI: https://doi.org/10.18472/cvt.20n3.2020.1826

Redalyc: http://www.redalyc.org/articulo.oa?

$\mathrm{id}=115464747007$

Recepción: 06 Junio 2020

Aprobación: 15 Diciembre 2020

\section{Resumo:}

Compreender como a culinária e a cultura alimentar de comunidades tradicionais influenciam o Turismo de Base Comunitária (TBC) é algo essencial. Objetivou-se analisar a relação entre culinária e cultura alimentar e o TBC, considerando a Rede Anfitriões do Litoral-PR como estudo de caso. O estudo analítico-descritivo foi realizado através de utilização de várias fontes de dados e formas de análise específicas, como análise qualitativa de relatórios de extensão realizada entre os anos de 2015 e 2020; análise quantitativa da interação dos internautas em postagens da página do Facebook da Rede; e dos resultados de sondagem com viajantes, via aplicação de questionário virtual. Constatamos que a oferta de refeições e experiências da culinária que expressam a cultura alimentar caiçara, divulgada no Facebook e programas televisivos, desperta elevado grau de interesse por parte dos viajantes interessados no TBC. Ademais, concluímos que a organização das experiências e refeições realizadas, sobretudo, por núcleos familiares dos Anfitriões, envolve inúmeras famílias das comunidades, sendo algo fundamental para a valorização da cultura alimentar.

Palavras-chave: Culinária Caiçara, Cultura alimentar, Rede Anfitriões do Litoral do Paraná, Turismo de Base Comunitária.

\section{AbstraCt:}

Understanding how the culinary and food culture of traditional communities influence on Community Based Tourism (CBT) is essential. This study aims to analyze the relationship between cuisine, food culture and the CBT, considering the "Hosts Network" of CBT, from the Paraná Coast, as a case study. The analytical-descriptive study was carried out using various data sources and specific forms of analysis, such as qualitative analysis of reports carried out between the years 2015 and 2020; quantitative analysis of the interaction by Internet users in posts from Facebook page and of the survey with travelers, via the application of a virtual questionnaire. We found that the offer of meals and culinary experiences that express the caiçara food culture, disseminated on the Facebook and television programs, arouses a high degree of interest by travelers interested in CBT. In addition, we conclude that the organization of the experiences and meals, carried out mainly by families, involves many communities, being something essential for the valorization of the communities' food culture.

KEYworDs: Caiçara cuisine, Food culture, "Host Network” of Paraná Coast, Community Based Tourism.

\section{Resumen:}

Comprender cómo la cultura culinaria y alimentaria de las comunidades tradicionales es influenciada por el Turismo Comunitario (TC) es essencial. El objetivo es analizar la relación entre culinaria, la cultura gastronómica y TC, considerando la Red Anfitriona del Litoral-PR como un estudio de caso. Se realizó un estudio analítico-descriptivo utilizando diversas fuentes de datos y formas específicas de análisis, como el análisis cualitativo de los informes de extensión realizados entre los años 2015 y 2020; análisis cuantitativo de la interacción entre usuarios de Internet en la página de la red del Facebook; y los resultados de la sonda con viajeros, mediante la aplicación de un cuestionario virtual. Observamos que la oferta de las comidas y experiencias culinarias que expresan la cultura caiçara, difundidas a través del Facebook y programas de televisión, despiertan alta tasa de interés de viajeros interesados en el TC. Además, concluimos que la organización de experiencias y comidas, realizadas principalmente por el núcleo familiar 
dos Anfitriones, son realizadas por muchas de las familias de las comunidades, siendo algo fundamental para la valorización de la cultura alimentaria.

Palabras clave: Cocina Caiçara, Cultura alimentaria, Red de Anfitriones de la Costa Paraná, Turismo comunitario.

\section{Aperitivos introdutórios}

Modelos e as práticas alimentares são o ponto de encontro entre culturas diversas, fruto da circulação de homens, mercadorias, técnicas, gostos de um lado para o outro do mundo. Digamos mais: as culturas alimentares (e as culturas em geral) são mais ricas e interessantes quanto mais os encontros e as trocas tenham sido vivazes e frequentes [...]. (Montanari, 2008, p. 189).

Encontros entre Anfitrióes e visitantes evidenciam as distinções relacionadas a preferências e hábitos alimentares, em momentos de escolha sobre o que se come, quando se come, onde se come, como e com quem se come. Tais decisões são realizadas tanto por aspectos objetivos - como o fato de pessoas terem tido acesso ou não a determinados alimentos -, como também por aspectos culturais e sociais que incluem crenças, regras sociais, aspectos socioeconômicos e tabus alimentares (Gimenes-Minasse, 2013). A riqueza dos encontros também é marcada no modo de compartilhar o alimento e conviver à mesa.

Portanto, o acesso e partilhas através da cultura alimentar[1] e culinária favorecem o Turismo de Base Comunitária (TBC), na medida em que este pode ser considerado como um modo de visita e hospitalidade que pressupõe uma relação dialogal entre Anfitriões e visitantes (Bursztyn, Bartholo \& Delamaro, 2009). As relações entre Turismo de Base Comunitária (TBC) e alimentação podem aprimorar as experiências dos visitantes e ao mesmo tempo, contribuir para o desenvolvimento comunitário. É necessário compreender que, o turismo gastronômico ou o turismo que tem como principal atrativo a alimentação, quando gerido de forma apropriada no contexto das experiências de TBC, pode tornar-se um atrativo estratégico para as experiências turísticas e, ao mesmo tempo, gerar um impacto positivo nas comunidades Anfitriãs.

São inúmeros os possíveis benefícios do turismo que tem como principal atrativo a gastronomia, entre eles destaca-se o reconhecimento e afirmação da cultura local, através da valorização de pratos e produtos típicos do território; o aumento da produção tradicional e incremento da economia local, dentre muitos outros fatores (Martins \& Costa, 2019). A valorização do patrimônio requer o engajamento das pessoas que habitam determinado território e dominam práticas culturais vinculadas à produção de alimentos e à confecção de determinadas receitas. Complementarmente, o reconhecimento da importância do patrimônio associado à cultura alimentar pode ser alcançado com medidas de proteção ao patrimônio[2] e, também, pela consequente valorização da cultura alimentar por parte do público consumidor, com destaque aos turistas.

Neste contexto, considera-se como pressuposto para realização do presente artigo, que o TBC é uma modalidade de turismo favorável à valorização do patrimônio associado à cultura alimentar de comunidades e para geração de benefícios advinda do uso turístico dos atrativos gastronômicos. Face a esta premissa, buscase analisar de que forma a culinária e cultura alimentar podem favorecer a configuração de atrativos turísticos associados ao TBC.

\section{A receita do artigo: Metodologia}

Realizar uma pesquisa científica é como preparar uma comida. É preciso seguir passos precisos, adicionar os ingredientes sob medida e constantemente verificar a harmonia dos sabores expressos pelos resultados, para assim obter um prato apetitoso. (Lobato, Aires, \& Ravena Cañete, 2019, p. 257).

O escopo central da pesquisa é apresentar um estudo de caso com viés exploratório, isto é “...lidar com uma completa variedade de evidências - documentos, artefatos, entrevistas e observações" (Yin, 1989, p. 19), no sentido de proporcionar maior familiaridade e compreensão sobre o Turismo de Base Comunitária, culinária 
e cultura alimentar, além de avaliar como a culinária e a cultura alimentar estão relacionadas ao TBC, a partir da Rede Anfitriões do Litoral do Paraná.

A Rede Anfitriōes do Litoral inclui três grupos de TBC já existentes na região, nos municípios de Paranaguá, Guaratuba e Guaraqueçaba (Figura 01) que, respectivamente, possuem as seguintes organizações não formais: a Rede Caiçara, formada em 2013; o Grupo Guarapés, constituído em 2016; e o Grupo Guaraguatá, formado em 2018. Como resultado das ações extensionistas da UFPR LITORAL para fomento do TBC na região, constatamos que aspectos da cultura alimentar e culinária caiçara constituem atrativos turísticos relevantes.

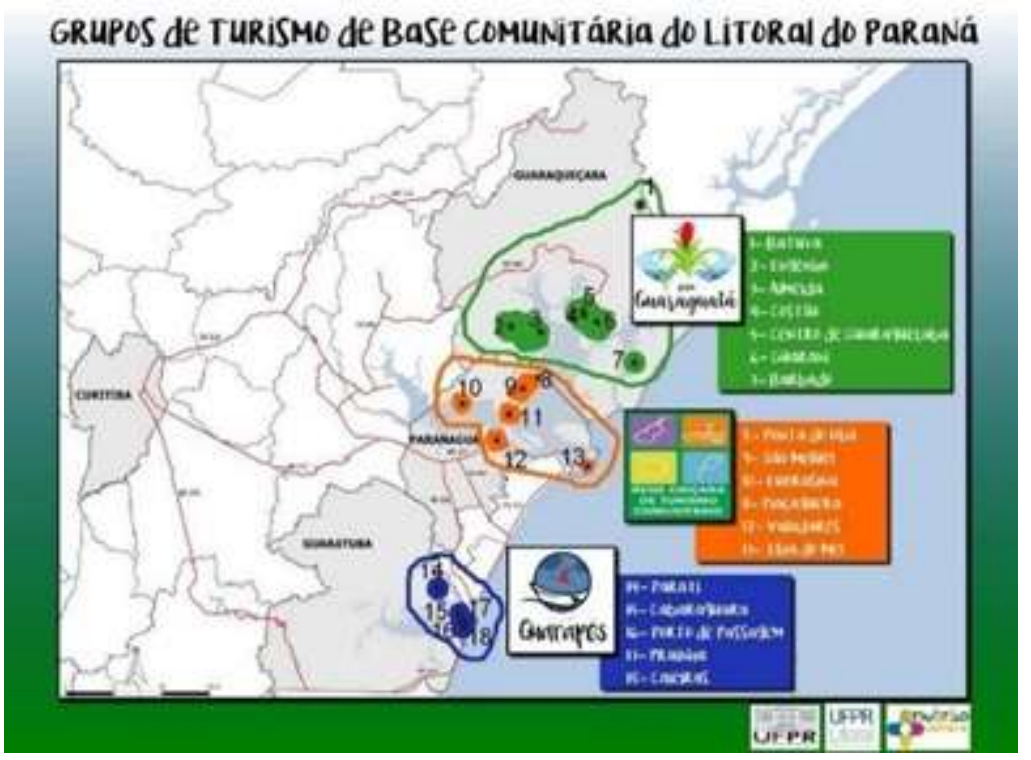

FIGURA 1

Mapa da Rede Anfitriões do Litoral

Acervo Projeto Mutirão UFPR, 2018

Reconhecemos a definição de Gândara, Gimenes e Mascarenhas (2009) para atrativos vinculados à gastronomia, os quais, segundo os autores, incluem a culinária regional, eventos gastronômicos, oferta de estabelecimentos de alimentos e bebidas diferenciados, além dos roteiros, rotas e circuitos gastronômicos. Neste contexto, o artigo apresenta uma análise sobre como culinária e cultura alimentar que caracteriza comunidades envolvidas na Rede Anfitriōes do Litoral do Paraná, propiciam a valorização da cultura alimentar e culinária, como expressão do patrimônio cultural do litoral paranaense e são capazes de despertar o interesse dos visitantes que buscam experiências de TBC.

Para analisar os potenciais benefícios do uso de atrativos gastronômicos para a comunidade local, considerar-se-á que o turismo de base comunitária pressupõe relações de colaboração, por meio de uma estrutura relacional inclusiva, favorecendo a ampliação das oportunidades geradas pelo turismo, na comunidade (Mendonça \& Irving, 2004; Burgos \& Mertens, 2015). Portanto, pretende-se descrever as características da cultura alimentar e culinária caiçara que caracterizam os atrativos da Rede Anfitriões, além de considerar como a organização destes atrativos beneficiam as famílias das comunidades.

Ademais, para avaliar a capacidade de tais atrativos de fato favorecerem a geração de fluxos turísticos às comunidades, há de se ponderar que, conforme Everett e Aitchison (2008) constam, a alimentação pode representar uma ferramenta de marketing para destinos turísticos. Para tanto, será realizada análise da página do Facebook da Rede Anfitrióes do Litoral do Paraná e análise de pesquisa com viajantes: "Perfil de viajantes que buscam experiências de Turismo de Base Comunitária, Ecoturismo ou Turismo de Aventura". Das 16 questões do formulário, duas foram analisadas, por terem vínculo com a cultura alimentar e culinária: "Qual 
é o seu grau de interesse em realizar as seguintes atividades/experiências?"[3] e "Sobre alimentação durante a viagem, assinale qual é ou quais são as opções de sua preferência" [4].

Do exposto, ao aproximar cultura alimentar, culinária e Turismo de Base Comunitária, esperamos que o estudo revele a relação indissociável entre essas temáticas, e que germine reflexões pertinentes, para análise de outros casos de TBC no Brasil e para definição de estratégias de gestão e marketing voltadas ao TBC.

\subsection{A entrada: descrição dos atrativos gastronômicos e modo como são organizados}

O cozinhar com o que tem demonstra não apenas a capacidade de adaptação da cultura caiçara mas também o respeito à disponibilidade e sazonalidade do que vem da terra, da água e da lama. (Ferreira \& Jankowsky, 2009, p. 10)

A singularidade da cultura alimentar tradicional caiçara no litoral do Paraná é evidenciada nas influências de diversas matrizes étnicas (indígena, europeia e africana) como resultado da conjuntura ocorrida durante a expansão da ocupação da costa paranaense, entre os séculos XVIII e XX, segundo (Clauzet, Ramires, \& Begossi, 2005). Conforme explicam (Ferreira \& Jankowsky, 2009), os indígenas originalmente influenciaram as formas de caçar mamíferos e aves, de coletar palmito, frutos e folhas; e cultivar raízes como o cará, a mandioca e a batata; a influência africana na cultura alimentar se dá pelo uso de milho, inhame, variados tipos de feijão, taioba ou taiá e pimentas; além do arroz e do preparo do pirão; e a europeia se expressa sobretudo no hábito de criar animais, como aves, suínos e gado, e na conservação dos alimentos com sal.

A alimentação caiçara evidencia a relação de comunidades ao mar, à terra e aos manguezais; e aos espaços "domésticos", como as roças e quintais. Sobre os modos de obtenção e produção dos alimentos, destacam-se as práticas de extrativismo, pesca, pequena agricultura, maricultura e coleta, praticadas principalmente por unidades familiares. No pretérito e com menor frequência ainda atualmente, os mutirões e guajus (reunião de famílias para troca de favores para a plantação de roça, por exemplo), denominam-se os trabalhos coletivos. A obtenção dos alimentos segue uma sazonalidade própria, de acordo com as estações do ano, fases da lua, maré, ciclo de migração de peixes como a tainha e período de abundância de determinados vegetais ou animais. Trata-se de uma culinária que remete aos conhecimentos da geração pretérita, que são renovados de acordo com o dinamismo da cultura alimentar, sobretudo com a introdução de alimentos industrializados, novos equipamentos e técnicas de cocção.

Conforme identificado em estudo realizado na comunidade de Barbados, Guaraqueçaba, por (Da Rocha, 2017), e também observado via interação entre pesquisadores e Anfitriãs, nota-se que determinadas receitas merecem destaque, pela frequência com que são elaboradas, tais como o peixe seco com banana, bolinhos de trigo, polenta com ostra, torta de banana, "mata-fome" (bolo de fubá) e bagre cozido. Há também, receitas preparadas esporadicamente, como o camarão no chuchu, camarão no mamão verde, a fubeca (bolinho frito preparado com fubá e água gelada), bolinho de cará, etc. Ainda segundo (Da Rocha, 2017), o modo preferido para o preparo de carnes e peixes é a fritura, principalmente dos pescados com escama, seguido do cozido, mais utilizado no preparo dos peixes sem escama (como, por exemplo, o bagre), seguido pelo assado. Além dos peixes, outros frutos do mar também são classificados como fonte alimentar e apresentam um valor social, como é o caso do caranguejo, do camarão e das ostras, também reconhecidos como "comidas de turista" (Da Rocha, 2017, p. 46). Ou seja, ainda que os visitantes não tenham acesso à comida frequentemente elaborada no dia a dia das comunidades, eles terão acesso aos preparos e alimentos considerados pelos Anfitrióes como sendo de maior qualidade e palatabilidade (Figura 2).

As receitas tradicionais são transmitidas através da oralidade, de geração para geração com o passar dos séculos, com as devidas adaptações adquiridas decorrentes de formas de uso do solo, legislações ambientais, configurações das famílias, acesso aos utensílios e técnicas utilizadas para preparo e mudanças nos hábitos alimentares. 

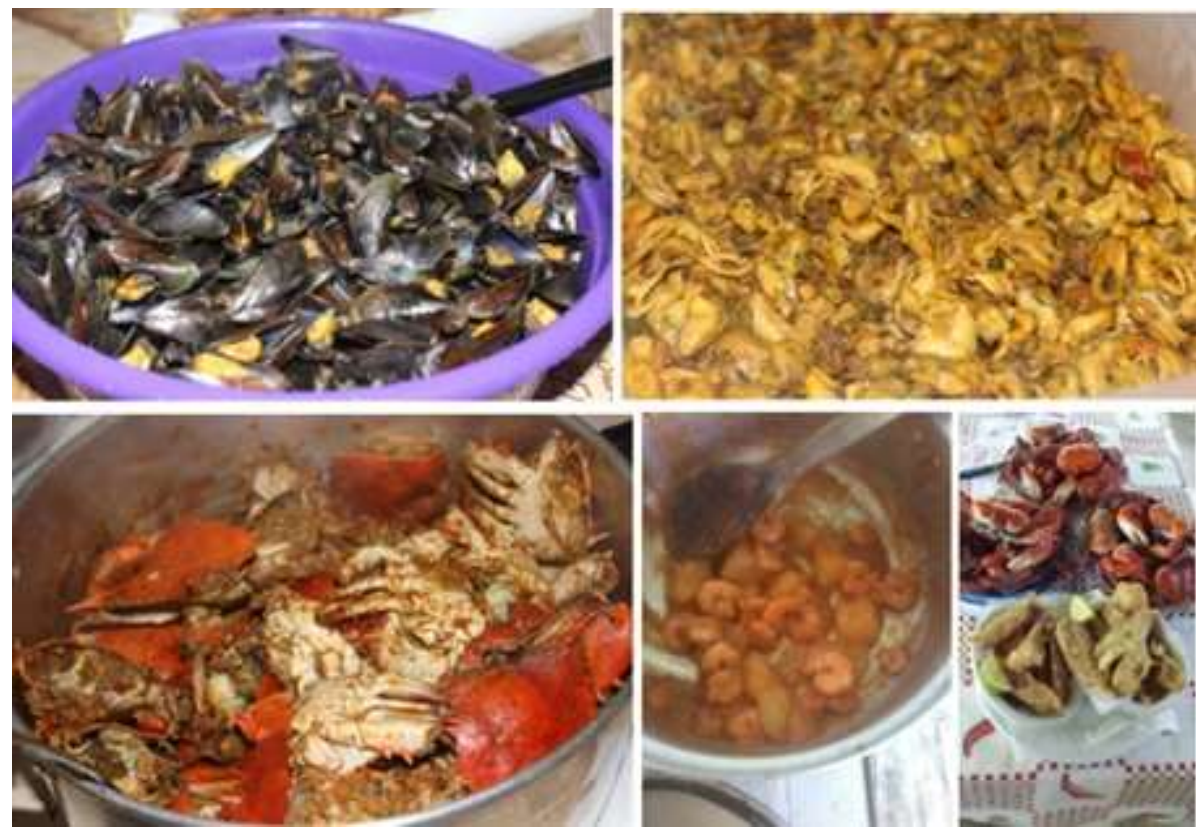

FIGURA 2

Insumos caiçaras frequentemente ofertados para os visitantes. Da esquerda para a direita (linha 01): mariscos e ostras; (linha 02): siri, camarão, peixe fresco e caranguejo. Acervo Projeto Mutirão, 2018 e Anfitriã Rosália Lopes, 2020.

A culinária caiçara está vinculada ao uso dos insumos disponíveis nos ambientes costeiros em determinadas épocas e estações do ano e, consequentemente, aos métodos utilizados para conservação e preparo dos alimentos, adaptados conforme mudanças do tempo e do espaço caiçara.

\section{Prato Principal: Análises gerais e discussão}

\subsection{Os atrativos turísticos gastronômicos na Rede Anfitrióes do Litoral}

Como parte da programação dos passeios voltados aos viajantes, é comum a oferta de atividades que valorizam a tipicidade e as particularidades culturais da culinária, tais como: passeios de barco para conhecer a pesca artesanal, visita aos manguezais, oportunidade de cozinhar com pescadores e produção de farinha de mandioca. Tendo em vista que a organização dos modos produtivos está centrada nas unidades familiares, de modo geral são as famílias que organizam as refeições e ou as atividades vinculadas à culinária, em espaços domésticos, como cozinha e varanda; de propriedade familiar, como restaurantes e hospedagens familiares; ou espaços comunitários, como Mercado Municipal de Guaraqueçaba e sede da Associação de Moradores do Costão. Geralmente, mulheres preparam refeições com os produtos disponíveis em determinada época do ano, envolvendo familiares ou outras famílias para aquisição de alimentos como peixe, frango caipira, farinha de mandioca, marisco e/ou caranguejos. 


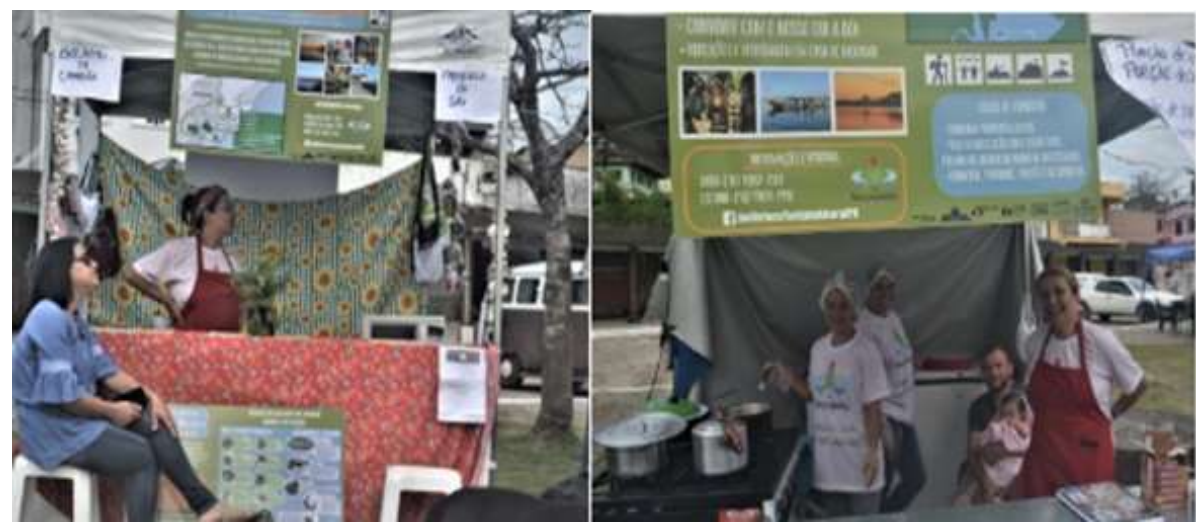

FIGURA 3

Anfitriãs com barracas que comercializam produtos típicos, em evento denominado "Revive". A autora, 2019

O trabalho com o Turismo de Base Comunitária é, assim como outras atividades tradicionais, gerido e organizado nos núcleos familiares. Ainda assim, durante as ações de pesquisa-ação, foi possível identificar algumas iniciativas pontuais que favoreceram a organização coletiva de experiências e venda de alimentos associados à culinária local, como a organização e participação em eventos culturais (Figura 3).

A seguir, serão apresentados três exemplos de experiências de visitação, as quais valorizam a cultura alimentar da comunidade e já foram realizadas por Anfitriōes e visitantes. Todas elas conectam o modo de vida e a cultura alimentar dos moradores às experiências de visitação de $\mathrm{TBC}$, constituindo importantes atrativos turísticos para a região.

\subsubsection{A pesca da tainha como atrativo da Ilha do Mel}

A pesca da tainha na Ilha do Mel está associada às heranças indígenas que influenciam a cultura caiçara, envolvendo instrumentos específicos e um conjunto de conhecimentos expressos nas técnicas de pesca, conforme explica o Instituto do Patrimônio Histórico e Artístico Nacional (IPHAN), (Martins, Frigo, Moscal, Zucon, \& Pinheiro, 2012). Atualmente, mesmo com diversas transformações no modo de pescar, a pesca da tainha ainda se mantém como um evento que remete às tradições passadas e ganha novos sentidos. A pesca da tainha e do lanço como pesca tradicional está ligada ao parentesco, à religiosidade e crenças, aspectos afetivos e morais. Conforme descrito na obra de (Martins et al., 2012), remete a um modo específico de organização social e divisão do trabalho entre as pessoas envolvidas, considerando os "donos da canoa", os espias (que vigiam a movimentação dos cardumes no mar); popeiro ou patrão da canoa (que pilota a canoa e enfrenta as arrebentações do mar), o chumbeiro (responsável por lançar a rede ao mar junto com o popeiro) e os proeiros, que remam e direcionam a canoa.

Anualmente, em períodos entre os meses de maio e julho, a pesca envolve inúmeras famílias para organização dos lanços e manutenção da pesca da tainha na ilha. São organizados acampamentos na praia do Miguel, com aproximadamente sete famílias, que vivem "à espera" dos cardumes. O acampamento é autorizado anualmente pelo órgão ambiental estadual Instituto Ambiental do Paraná (IAP). A rede de pesca conta com aproximadamente 250 braços de comprimento e seis braços de largura; assim como a rede e os apetrechos de pesca, a canoa que é tradicionalmente utilizada para tanto (Figura 4) pertence a famílias específicas da comunidade de Encantadas.

O preparo da tainha durante sua "safra" é predominantemente feminino e pode assumir diversas formas: recheada com farofa, defumada, peixe seco com banana ou "Azul Marinho" (feito com peixe defumado, banana madura ou verdolenga, tomate, temperos e farinha de mandioca). A tainha é considerada um "peixe 
do inverno", "um peixe forte" (por ter muita gordura). Os Anfitriões, desde 2019, passaram a reconhecer o valor cultural da pesca da tainha, fazendo desta prática, uma forma do visitante (Figura 4) conhecer as histórias dessa modalidade de pesca, o modo de divisão do trabalho para realização dos "lanços", tipo da embarcação e local onde se pesca a tainha.

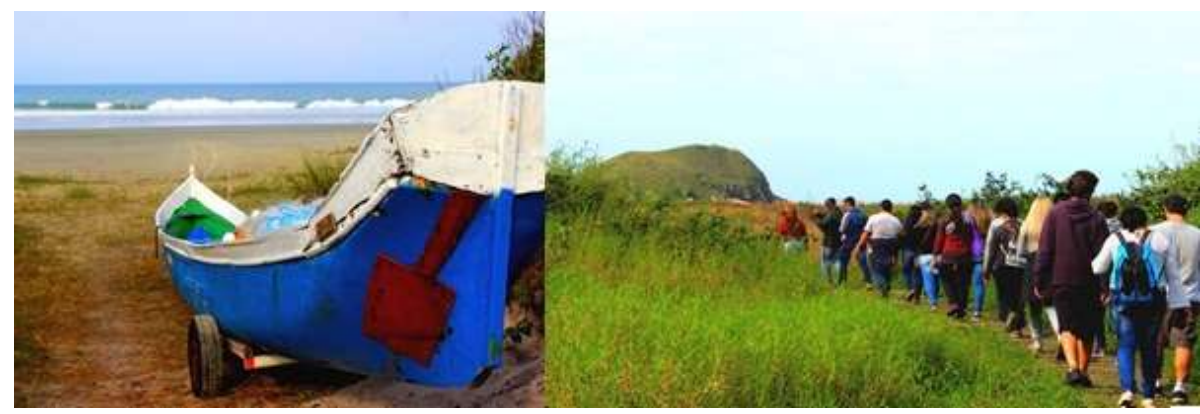

FIGURA 4

Experiência para conhecer a pesca da tainha na Ilha do Mel. Da esquerda pra direita: Canoa tradicional e rede artesanal utilizada para pesca da tainha na Praia do Miguel - Ilha do Mel. Anfitrião levando grupo para conhecer a pesca da Tainha, na Praia do Miguel. Acervo Projeto Mutirão, 2018

\subsubsection{A pesca do siri como atrativo turístico na Ilha de São Miguel-Paranaguá e no Costão- Guaraqueçaba}

A pesca do siri não exige um alto investimento em tecnologia de beneficiamento, ocorre durante o ano todo, utiliza sobretudo o trabalho familiar, com destaque ao trabalho desempenhado por mulheres (Anacleto et al., 2015). Esta modalidade de pesca é de suma importância para famílias do Costão, comunidade de Guaraqueçaba que concentra a segunda maior quantidade de pescadores no município de Guaraqueçaba (Mendonça, Lucena, Muehlmann, \& Medeiros, 2017).

No Costão, apesar de o turismo ainda ser incipiente, há de se considerar que existe uma organização coletiva do trabalho para receber os visitantes e valorizar a cultura alimentar associada ao siri, vinculando produtor, cozinheiras e viajantes, conforme experiência na comunidade do Costão, em fevereiro de 2020. Como parte da programação definida por uma Anfitriã, o almoço foi realizado por mulheres da Associação de Moradores do Costão foi preparado à base de peixe fresco pescado pelo marido de uma das cozinheiras, bem como de "carne de siri", palmito, farinha e outras iguarias cujos insumos foram adquiridos diretamente do produtor; processos parcialmente expostos (Figuras 5 e 6 ). 


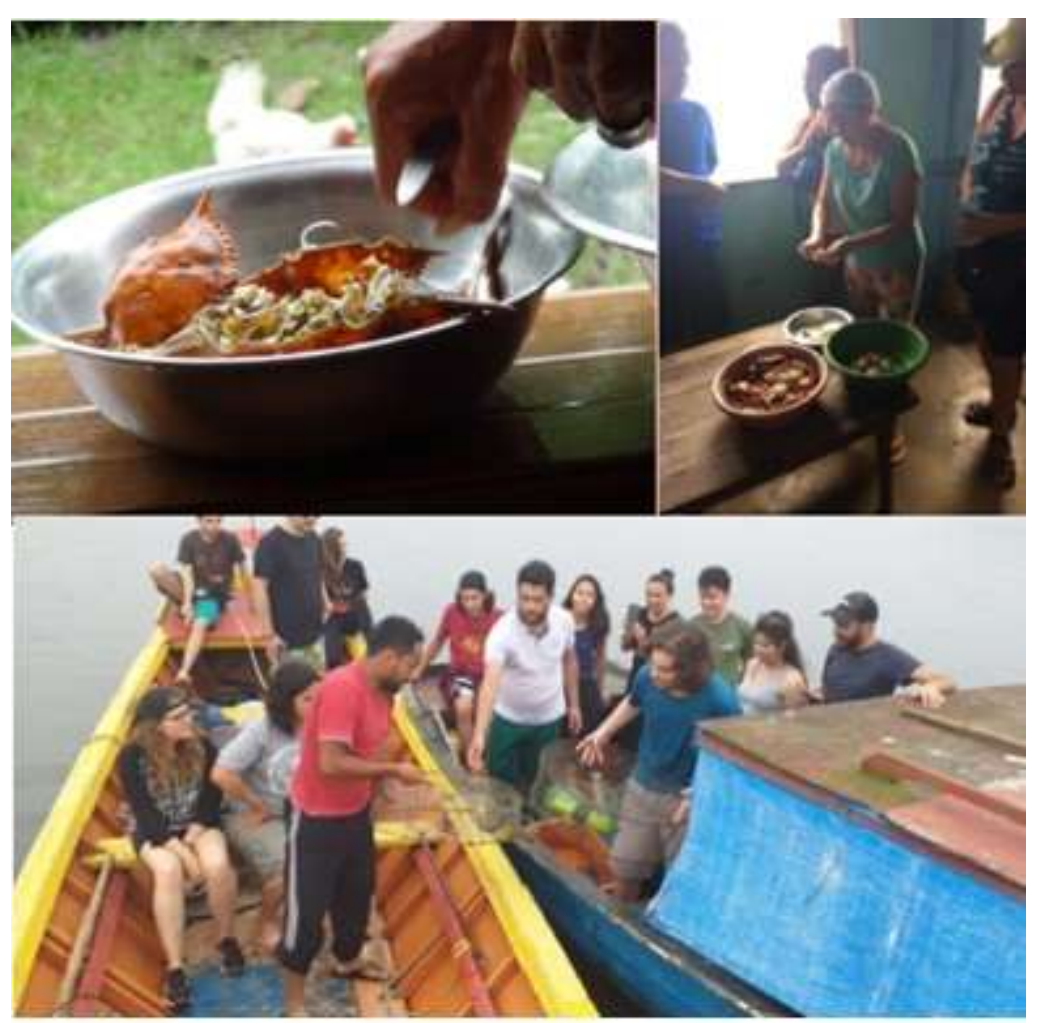

FIGURA 5

Da esquerda para a direita, de cima para baixo: processo de demariscar, visitantes vendo moradora do Costão (Guaraqueçaba) demariscando; visitantes vendo como ocorre a pesca do siri em Guaraqueçaba, acompanhados de pescadores, no Roteiro turístico no Costão-Guaraqueçaba Fonte: A autora, 2019 e Acervo Projeto de Extensão Governança participativa para o Turismo de Base Comunitária, Ecoturismo e Turismo de Aventura no Litoral do Paraná, 2019. 


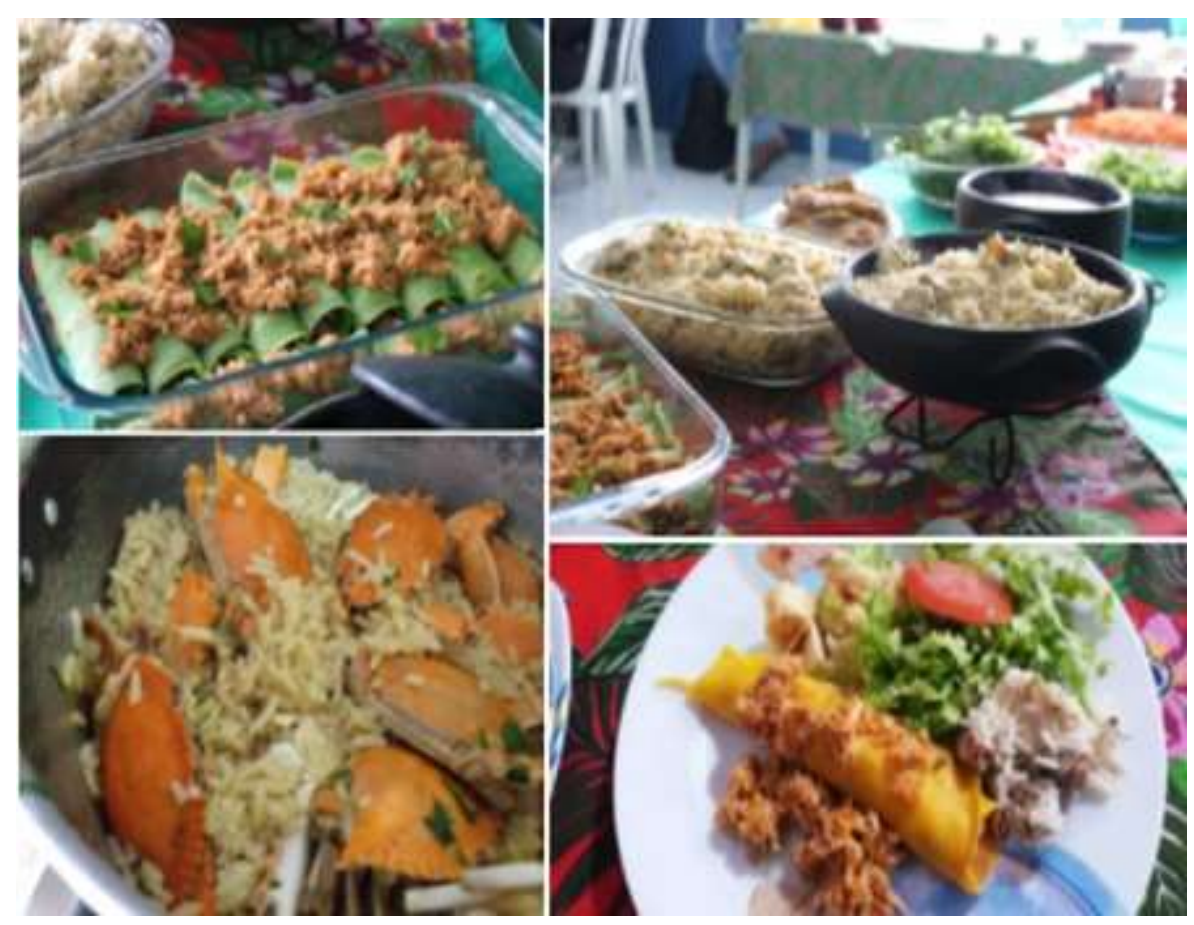

FIGURA 6

Refeições preparadas a base de siri na comunidade do Costão - Guaraqueçaba - PR. Anfitriã Joice Mendes, 2020.

\subsubsection{A produção da farinha de mandioca associada ao turismo cultural no litoral}

Segundo (Denardin et al., 2009), durante a primeira década dos anos 2000 havia um total de 133 farinheiras artesanais em todo o litoral do Paraná, sendo que 54 estavam com status ativa, 56 funcionando apenas para o autoconsumo, 15 inativas e oito eram comunitárias. As casas de farinha ou farinheiras artesanais constituem espaços de importância histórica para inúmeras comunidades do litoral do Paraná, favorecendo a produção de alimentos para autoconsumo, e envolvem produções familiares ou comunitárias e, com o turismo, são vistas como espaços culturais. Constatou-se também, via diálogos e visitas às comunidades onde habitam os participantes da Rede Anfitrióes do Litoral do Paraná - Turismo de Base Comunitária, que muitas das casas de farinha estão inativas ou não possuem mais a mesma importância para a dinâmica do território.

A farinha artesanal produzida por caiçaras tem uma textura diferenciada da industrializada, comumente encontrada à venda em supermercados de todo o país. Portanto, a granulação já possibilita identificar sua procedência. A farinha artesanal representa não só uma fonte de renda para muitos caiçaras que atuam no/ participam do TBC no litoral, como também é a base de um dos principais preparos culinários da cultura alimentar, o pirão.

Em Guaratuba, na comunidade do Cabaraquara, existe uma única farinheira em funcionamento, das 12 que havia no pretérito. A mandioca é plantada pelo agricultor e Anfitrião Denilson Alves e a farinha é produzida por sua esposa, Vanderleia Alves (Figura 08). 


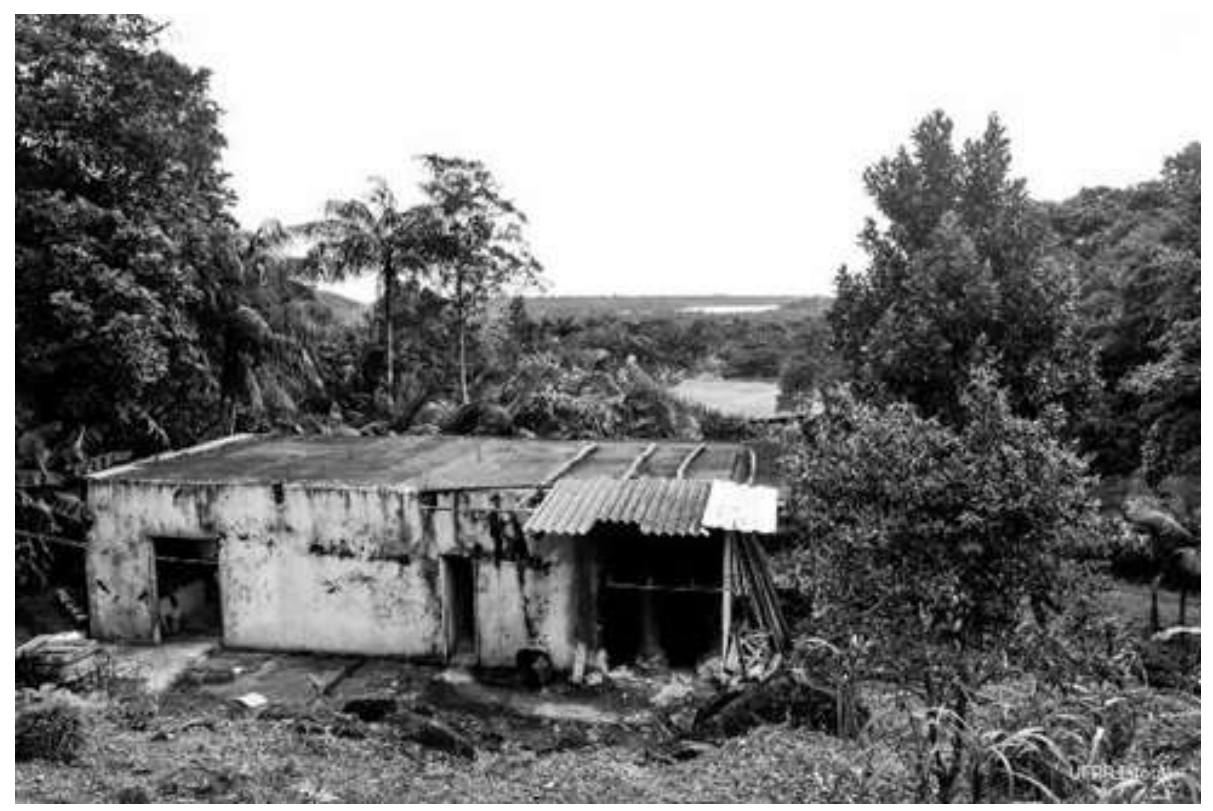

FIGURA 7

Casa de farinha de Vanderléia da Rocha Alves e Denilson Alves.

UFPR LITORAL, 2017.

O processo de produção da farinha artesanal de mandioca e do biju (tapioca crocante) se inicia quando a mandioca é colhida e descascada. Conforme as (Figuras 8, 9 e 10), os visitantes que participam da confecção da farinha podem participar de modo "demonstrativo" de cada uma dessas etapas. Em virtude das diversas transformações tecnológicas e socioculturais, o modo de fabricar a farinha comumente tem sido adaptado.

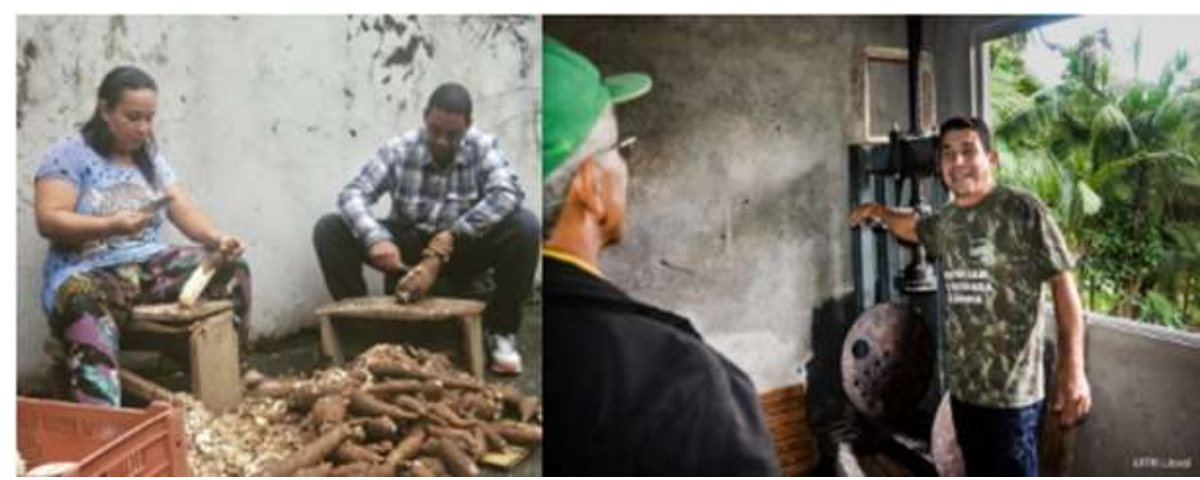

FIGURA 8

Vivências e saberes nas casas de farinha que compõem o TBC no litoral-PR. Anfitriã Vanderléia da Rocha Alves e visitante/pesquisador "ralando" a mandioca.

Anfitrião Denilson Alves mostrando sobre o funcionamento da prensa manual.

A autora, 2018 e Acervo Projeto Fortalecimento do Empreendedorismo, inovação e gestão familiar do turismo na Baía de Guaratuba. 


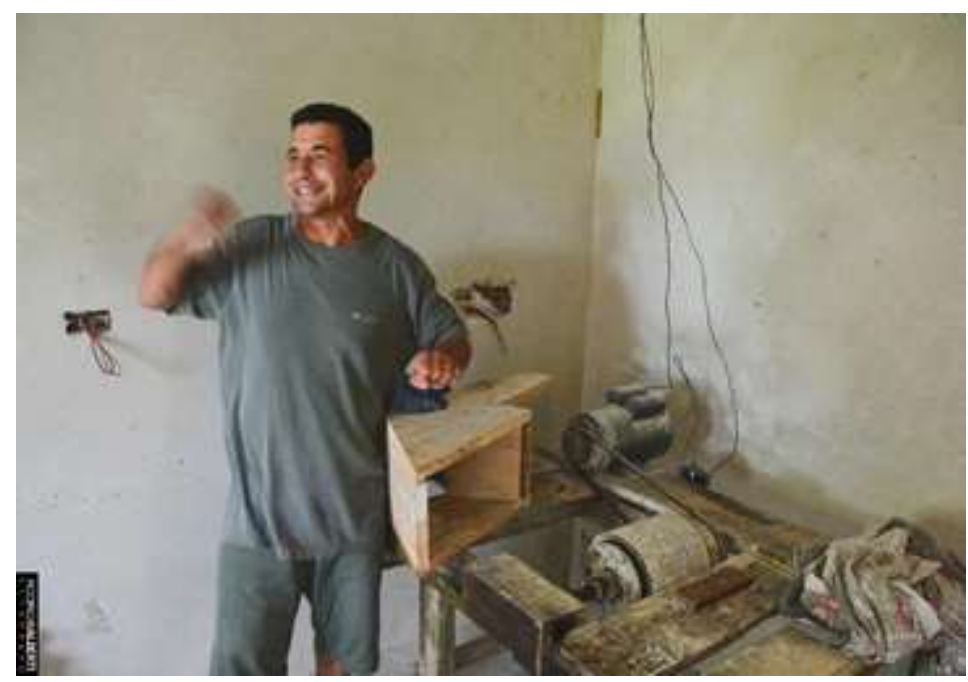

FIGURA 9

Anfitrião Denilson Alves explicando sobre a etapa de "ralar" a mandioca na casa de farinha do Sítio Alvorada. Universidade Federal do Paraná (UFPR) 2018.

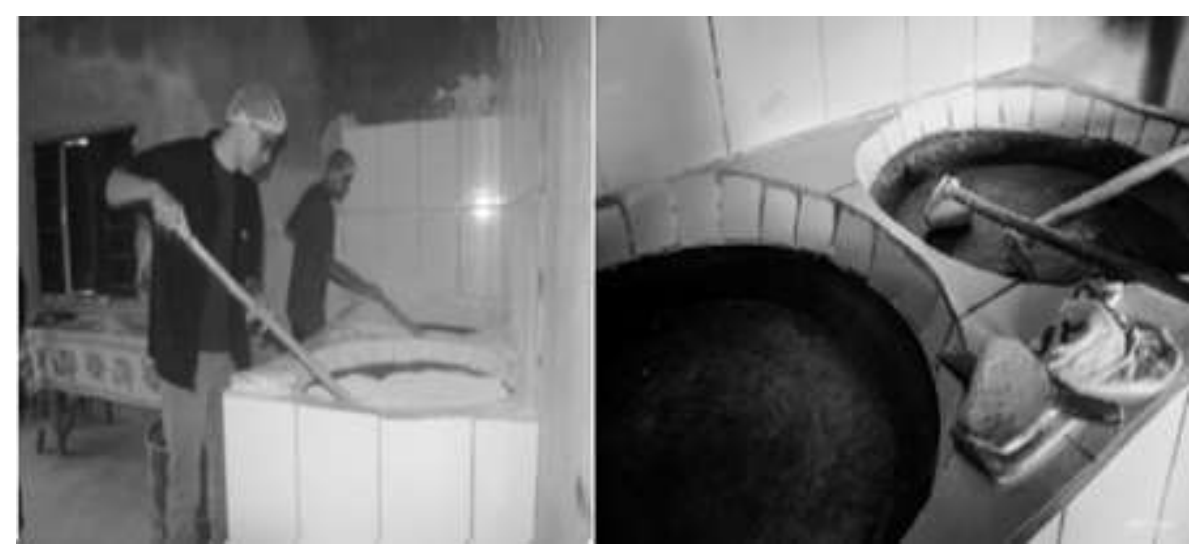

FIGURA 10

Visitantes "forneando" a farinha na casa de farinha da Vanderléia da Rocha Alves. A autora, 2019. 2. Acervo Projeto Mutirão, 2019 e UFPR LITORAL, 2017.

Em comunidades de Guaraqueçaba, tais como Almeida e Barbado, há possibilidade de conhecer e participar do processo de confecção da farinha. No entanto, por escassez da produção de mandioca nesses locais, a experiência é comprometida, pois, para tanto, é necessário adquirir o produto no mercado ou com outras comunidades.

A partir da análise dos atrativos constata-se que eles apresentam singularidade, pois refletem o patrimônio associado à cultura alimentar que é expresso pelas práticas associadas à obtenção de alimentos e insumos de relevância para a culinária caiçara. Além das experiências de visitação já descritas, que veiculam cultura alimentar e TBC, como resultado da análise dos atrativos, definimos duas categorias de atrativos gastronômicos identificados nas comunidades da Rede Anfitriões: (i) oferta de refeições; e (ii) a realização de experiências de visitação. O quadro apresentado a seguir (Quadro 01) demonstra que 15 das comunidades que integram a Rede Anfitriões oferecem experiências de visitação vinculadas à culinária. 
QUADRO 01

Síntese da oferta de experiências culinárias na Rede Anfitrióes do Litoral-PR.

\begin{tabular}{|c|c|c|}
\hline \multicolumn{3}{|c|}{ GRUPO GUARAGUATÁ - GUARAQUEÇABA, PR } \\
\hline Local & Oferta de culinária típica & Experiências de visitação \\
\hline Engenho & $\begin{array}{l}\text { Preparos tradicionais da região } \\
\text { como pescados e carne de siri no } \\
\text { fogão a lenha; garapa feita na } \\
\text { hora. }\end{array}$ & $\begin{array}{l}\text { Visita ao engenho tradicional } \\
\text { da comunidade para participar } \\
\text { do processo de confecção de } \\
\text { farinha e caldo de cana. }\end{array}$ \\
\hline Almeida & $\begin{array}{l}\text { Refeições à base de peixes } \\
\text { tradicionais da região, preparos } \\
\text { variados com ostras, camarão, } \\
\text { caranguejo (de dezembro a } 15 \\
\text { de março), siri, mariscos e sucos } \\
\text { naturais. }\end{array}$ & $\begin{array}{l}\text { Visita ao "plantio de ostras" e } \\
\text { roça de abacaxi. Pesca } \\
\text { artesanal com canoa - vivência } \\
\text { com mulheres da comunidade. }\end{array}$ \\
\hline Costão e Centro & $\begin{array}{l}\text { Refeiçŏes elaboradas com peixe, } \\
\text { siri, bolinho de banana. }\end{array}$ & $\begin{array}{l}\text { Vivência do Siri e visita ao } \\
\text { mercado municipal que } \\
\text { comercializa produtos locais. }\end{array}$ \\
\hline Barbado & $\begin{array}{l}\text { Refeiçŏes elaboradas com peixe } \\
\text { fresco, ostras, siri, camarão e } \\
\text { caranguejo. Café com pão, } \\
\text { bolinho de banana e frutas. }\end{array}$ & $\begin{array}{l}\text { Possibilidade de pilar arroz, } \\
\text { visitar casa de farinha e } \\
\text { conhecer sobre a pesca } \\
\text { artesanal. }\end{array}$ \\
\hline \multicolumn{3}{|c|}{ REDE CAIÇARA - PARANAGUÁ E PONTAL DO PARANÁ, PR } \\
\hline Local & Oferta de culinária típica & Experiências de visitação \\
\hline Ponta do Ubá & $\begin{array}{l}\text { Pratos típicos da cultura } \\
\text { alimentar. }\end{array}$ & $\begin{array}{l}\text { Trilha ao manguezal e pesca } \\
\text { artesanal. }\end{array}$ \\
\hline São Miguel & $\begin{array}{l}\text { Pratos típicos da cultura } \\
\text { alimentar. }\end{array}$ & $\begin{array}{l}\text { Pesca artesanal, extração da } \\
\text { carne do siri (demariscar); } \\
\text { oficina de cestaria. }\end{array}$ \\
\hline Eufrasina & $\begin{array}{l}\text { Pratos típicos da cultura } \\
\text { alimentar local. }\end{array}$ & Pesca artesanal. \\
\hline Valadares & $\begin{array}{l}\text { Barreado e pratos típicos à base } \\
\text { de pescados Associação } \\
\text { Mandicuera. }\end{array}$ & $\begin{array}{l}\text { Circuito no manguezal e } \\
\text { vivência da pesca artesanal. }\end{array}$ \\
\hline $\begin{array}{l}\text { Encantadas e } \\
\text { Praia do Miguel }\end{array}$ & $\begin{array}{l}\text { Refeiçôes servidas por } \\
\text { restaurantes parceiros da Rede } \\
\text { Anfitriões do Litoral. }\end{array}$ & $\begin{array}{l}\text { Visita ao acampamento dos } \\
\text { pescadores da tainha para } \\
\text { conhecer sobre as técnicas, } \\
\text { conhecimento, organização e } \\
\text { petrechos de pesca. }\end{array}$ \\
\hline Café Guaraguaçu & $\begin{array}{l}\text { Comercialização de lanches } \\
\text { panificados, tortas e receitas } \\
\text { típicas da regiấo. }\end{array}$ & $\begin{array}{l}\text { Momentos de discussão sobre a } \\
\text { cultura caiçara com Dona } \\
\text { Conceiçấo. }\end{array}$ \\
\hline \multicolumn{3}{|c|}{ GRUPO GUARAPÉS - GUARATUBA, PR } \\
\hline Local & Oferta de culinária típica & Experiências de visitação \\
\hline Parati & $\begin{array}{l}\text { Refeições servidas em } \\
\text { restaurante. }\end{array}$ & $\begin{array}{l}\text { Criação de abelhas e pesca } \\
\text { artesanal com tarrafa. }\end{array}$ \\
\hline $\begin{array}{l}\text { Porto de } \\
\text { Passageme } \\
\text { Cabaraquara }\end{array}$ & $\begin{array}{l}\text { Refeições à base de mandioca, } \\
\text { verduras da roça, vegetarianas } \\
\text { ou com carne de peixe ou frango } \\
\text { caipira. Sorvete de aipim. }\end{array}$ & $\begin{array}{l}\text { Possibilidade de eventualmente } \\
\text { participar da confecção de } \\
\text { farinha artesanal, na casa de } \\
\text { farinha. Produção de caldo de } \\
\text { cana. Oportunidade de } \\
\text { conhecer cultivo de ostras. } \\
\text { Vivência sobre pesca artesanal } \\
\text { no estuário. }\end{array}$ \\
\hline Caieiras & $\begin{array}{l}\text { Refeiçŏes à base de peixes e } \\
\text { frutos do mar. }\end{array}$ & $\begin{array}{l}\text { Vivência da pesca artesanal no } \\
\text { estuário. }\end{array}$ \\
\hline
\end{tabular}


Os autores, 2020.

A lista de atrativos revela a diversidade de experiências e de refeições que valorizam a cultura alimentar e culinária caiçara, ofertadas nas diversas comunidades e grupos que integram a Rede dos Anfitriōes. São atrativos vinculados diretamente às características culturais e ambientais das comunidades.

\section{$3.2 \mathrm{O}$ interesse dos visitantes}

A encontrabilidade se caracteriza como uma ferramenta para atrair turistas em potencial na web, como, também, "é capaz de identificar novas estratégias e promoção de custo, ao promover no processo de divulgação, identificando o público-alvo com mais eficiência, determinando os objetivos e criando mensagens designadas para atrair novos turistas" (Neves et al., 2019, p. 45). Para tanto, realizou-se pesquisa interna na rede social Facebook da Rede Anfitrióes do Litoral do Paraná - Turismo de Base Comunitária, plataforma digital na qual se objetivou a repercussão das matérias produzidas sobre cultura alimentar dos caiçaras.

Não obstante, com base na análise dos resultados do formulário online elaborado pelo discente no curso superior de Tecnologia em Gestão de Turismo (Souza, 2020, p. n.p.), "Perfil de viajantes que buscam experiências de Turismo de Base Comunitária, Ecoturismo ou Turismo de Aventura", foram identificados resultados de importância para compreensão do interesse dos viajantes em provar culinária, local de preferência para isso e grau de interesse em participar de experiências associadas à cultura alimentar.

De acordo com resultados, (Souza, 2020, p. 83) aponta que a opção de "Provar culinária local e aprender sobre a cultura alimentar" foi indicada por $82,7 \%$ dos 197 respondentes da pesquisa como algo que desperta "muito interesse", sendo que essa mesma quantidade de pessoas indicou na pesquisa que possui "muito interesse" em "Conhecer comunidades tradicionais e práticas culturais que possibilitem vivenciar o modo de vida local". Ademais, ainda segundo (Souza, 2020, p. 83), 14,7\% indicaram ter "interesse médio" e somente 2,5\% dos entrevistados afirmaram ter "pouco interesse" nesse tipo de experiência. Portanto, é possível afirmar que, na perspectiva dos viajantes, a culinária constitui um importante atrativo e fator motivador para as viagens.

Tal constatação está diretamente associada aos resultados obtidos com a pergunta de múltipla escolha, sobre as opções de preferência para alimentação durante as viagens, (Gráfico 1). Como resposta à questão, as alternativas vinculadas à culinária local tiveram destaque, sendo que "Comer em restaurante na comunidade e provar culinária local" foi indicada por 69,3\% dos 202 respondentes; e "Comer em casa de morador e provar culinária local", por 58,9\% deles. Os resultados em relação às demais opções de resposta foram: "Comer em restaurante ou casa de morador, com adaptações da culinária local”, opção indicada por 39,3\% dos respondentes; "Levar minha comida para cozinhar", opção marcada por $20 \%$ deles; e "Comer em restaurantes que não são da comunidade”, opção de resposta de $11,9 \%$ das pessoas que preencheram o formulário (Gráfico 1). 


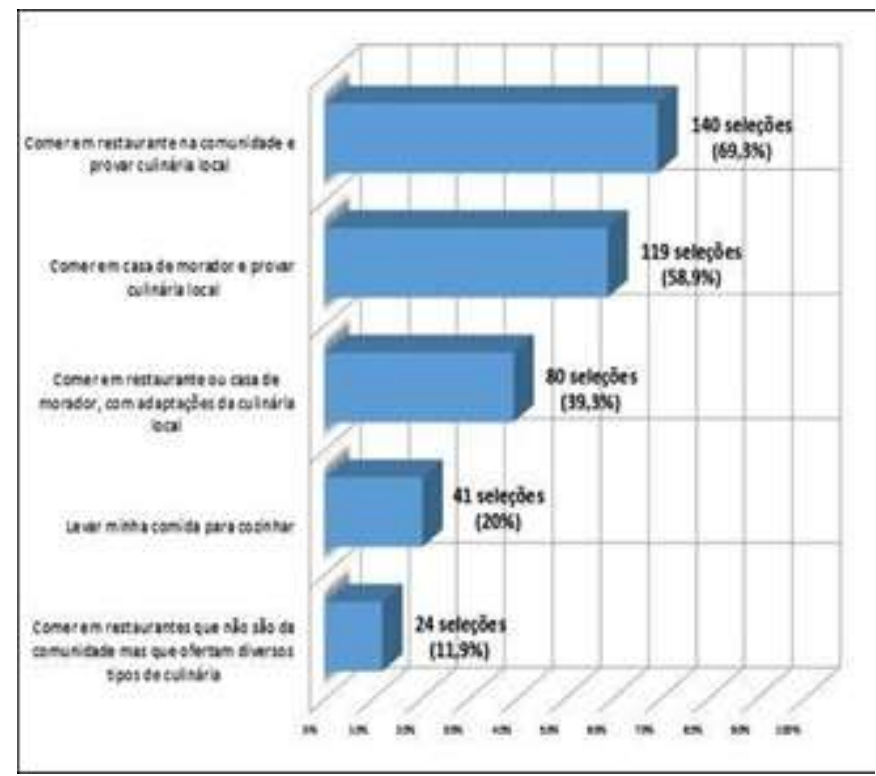

GRÁFICO 1

Análise dos resultados voltados à alimentação do formulário online.

Souza e Projeto de Extensão Governança participativa para o Turismo

de Base Comunitária, Ecoturismo e Turismo de Aventura (2020).

Complementar ao resultado das respostas obtidas com base no formulário de pesquisa citado anteriormente, se realizou análise da página do Facebook Rede Anfitriões do Litoral do Paraná - Turismo de Base Comunitária, perfil em funcionamento desde outubro de 2018 e composta em setembro de 2020 por 1.126 seguidores dos seguintes países: Brasil; Portugal; Argentina; Paraguai; Austrália; México; Itália; Reino Unido, Polônia e Canadá. Ao avaliar o grau de interesse dos seguidores e visitantes da page por publicações que envolvem cultura alimentar caiçara entre outros produtos turísticos ofertados, a partir das métricas disponibilizadas pela ferramenta Analytics do Facebook, as postagens que se associam a culinária tiveram quantidade de interações mais elevada. Segundo dados obtidos, no mês de abril de 2019 quando a página contava com 227 seguidores, uma postagem relacionada à "tríade" de grupos de TBC no litoral-PR atingiu 671 visualizações e 19 compartilhamentos. Por outro lado, em fevereiro de 2020 quando a mesma contava com 850 seguidores, uma publicação referente aos preparos culinários ofertados pelo grupo Guaraguatá atuante na comunidade de Barbados em Guaraqueçaba atingiu 9.527 visualizações, com destaque aos 70 compartilhamentos. Nesse sentido, ao realizar tal comparativo de atrativo, se evidencia o principal interesse dos internautas que acompanham a Rede Anfitrióes do Litoral do Paraná.

A promoção da culinária também foi alavancada via programas televisivos que retrataram o processo de confecção de determinadas receitas, como é o caso do Estúdio $\mathrm{C}$ apresentado pela RPC, afiliada à Rede Globo no Paraná (à direita na Figura 11), do dia 07/12/2019, que apresentou o processo de confecção da farinha de mandioca e do sorvete artesanal de mandioca. Também foram de suma importância a aparição dos Anfitriões e a valorização da cultura alimentar no Programa PLUG (à esquerda na Figura 11), através da mesma emissora de televisão, das seguintes datas e que trataram dos seguintes temas: Dia 20/01/2018 sobre a confecção de bolinho de milho na comunidade do Parati, Guaratuba; sobre o cultivo de ostras do Cabaraquara. Do dia 16/02/2019 sobre a extração de ostras na comunidade do Almeida-Guaraqueçaba. No dia 18/01/2020 sobre o Café Caiçara ofertado no Guaraguaçu, Pontal do Paraná. 


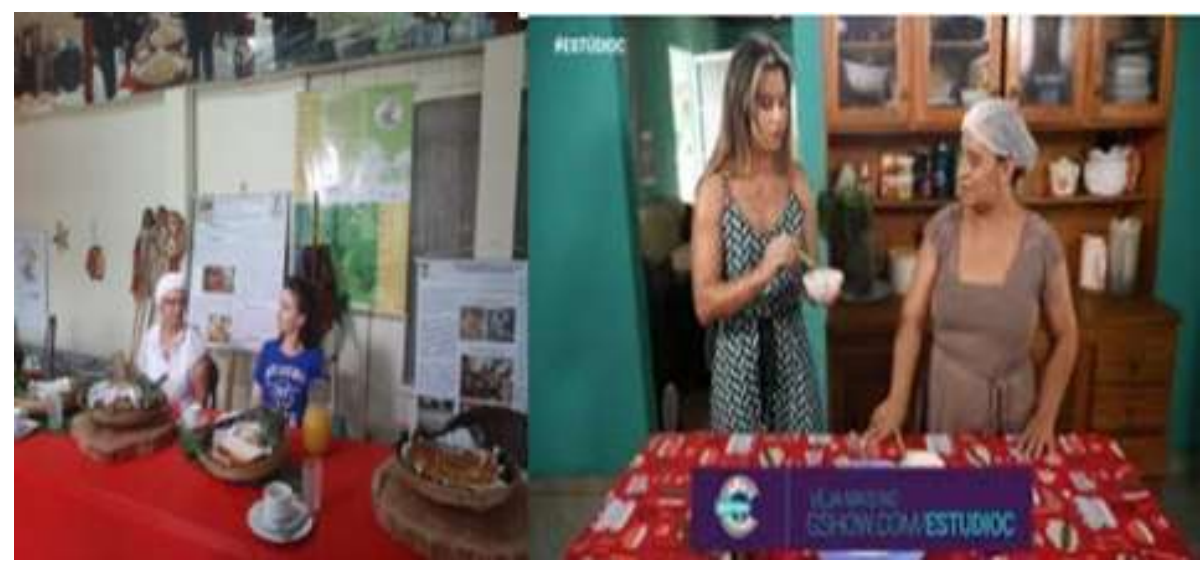

FIGURA 11

Anfitriãs caiçaras do litoral paranaense na programação da Rede Globo. À esquerda, a Anfitriã Dona Conceição em entrevista para o programa PLUG. À direita, a Anfitriã Vanderléia da Rocha Alves em entrevista para o programa Estúdio C. Anfitriã Dona Conceição, 2019; 2. Programa Estúdio C, 2019.

Portanto, os resultados da análise do marketing demonstram que os viajantes que buscam por opções de viagem nas comunidades da Rede Anfitriōes do Litoral possuem, conforme fundamentado nos dados obtidos através do formulário de pesquisa, "muito interesse" em "provar a culinária local e aprender sobre a cultura alimentar".

\section{Para finalizar, uma Sobremesa conclusiva.}

O TBC, por conta de suas características intrínsecas que reforçam a importância do intercâmbio cultural e do protagonismo das comunidades na organização das experiências de visitação, reforça a interação do visitante com o local visitado, a partir do uso turístico da cultura alimentar. Portanto, a cultura alimentar e a culinária tradicional constituem atrativos turísticos singulares, capazes de valorizar o patrimônio cultural e capilarizar os benefícios do turismo entre famílias de uma mesma comunidade. Tais constatações são fruto da investigação que evidencia o fato de a culinária tradicional e experiências vinculadas à cultura alimentar caiçara constituírem atrativos turísticos fundamentais para a dinâmica das comunidades Anfitriãs e, ao mesmo tempo, serem propostas de visitação que despertam elevado grau de interesse por parte dos viajantes.

Sobre o caso específico da Rede Anfitriōes do Litoral do Paraná, para nós é evidente que os Anfitriōes desempenham um papel importante como "intérpretes" da cultura alimentar, visto que os mesmos detêm habilidades culinárias e hospitalidade para interagir com os visitantes. Atualmente, as experiências culinárias são organizadas e concebidas pelos núcleos familiares dos Anfitriões, os quais estabelecem vínculos diretos e por iniciativa própria com os produtores (quando não são eles próprios) da comunidade ou região. Apesar de constatarmos inúmeras ações de divulgação da cultura alimentar da região via redes sociais e programas televisivos, é possível ampliar a vinda de visitantes interessados nesse tipo de experiências.

Como sugestão de estratégias que poderiam ser adotadas pela Rede Anfitrióes ou outras iniciativas de TBC, reconhecemos a importância de ampliar as ações que envolvem famílias de uma mesma comunidade. Outra estratégia passível de ser adotada é a ampliação de parcerias comerciais, governamentais ou não governamentais, que poderão favorecer o marketing direcionado para pessoas que buscam por produtos de qualidade, organização dos atrativos e reconhecimento da qualidade dos produtos alimentícios e da cultura alimentar. A exemplo das ações vinculadas ao fortalecimento institucional, aponta-se para a pertinência de serem estabelecidos processos de reconhecimento da qualidade dos produtos ou do patrimônio associado à cultura alimentar, tais como certificações, integração a movimentos como Slow Food (2007) e formulação de 
políticas públicas de reconhecimento e salvaguarda do patrimônio cultural associado à culinária, como sugere o Anfitrião da Ilha do Mel, sobre a pesca da tainha. Ademais, seria oportuno adotar estratégias de marketing que valorizem ainda mais as experiências culinárias como opção de visitação às comunidades; ampliar as formas de organização do trabalho de modo coletivo e que integre produtores e consumidores; além dos aspectos vinculados às políticas públicas que reconheçam a qualidade dos produtos e a singularidade das práticas que integram a cultura alimentar dos caiçaras paranaenses. Tais ações poderão favorecer a valorização e a utilização dos produtos locais, de modo a ampliar o "efeito multiplicador" da renda gerada com o turismo na economia comunitária, além de gerar valor agregado às atividades econômicas já desenvolvidas.

Concluímos, portanto, que a presente análise revela a relação interdependente entre Turismo de Base Comunitária, cultura alimentar e culinária tradicional. Reforçamos que, para que essa combinação de elementos traga os resultados que as comunidades esperam, não há receita pronta, optamos por sugerir que, assim como os caiçaras preparam suas refeições com os insumos da "safra", que tenhamos um olhar atento e respeitoso às condições do território, às decisões familiares e comunitárias e aos interesses dos visitantes.

\section{REFERÊNCIAS}

Anacleto, A., Baptista-Metri, C., Gonçalves, T.P., Calado, A.M., Rosário, E.S., Pontes, M. \& Neves, P.R. (2015). Extrativismo do siri com gaiolas no litoral paranaense: implicaçôes socioeconômicas (13). Anais do XXXII International Sodebras Congress, Curitiba, 10(111).

Burgos, A.; Mertens, F. A perspectiva relacional na gestão do turismo de base comunitária: o caso da Prainha do Canto Verde. Caderno Virtual de Turismo. Rio de Janeiro, v. 15 n.1., p.81-98, abr. 2015

Bursztyn, I., Bartholo, R. \& Delamaro, M. (2009). Turismo para quem? Sobre caminhos de desenvolvimento e alternativas para o turismo no Brasil. In: Bartholo, R., Sansolo, D.G. \& Bursztyn, I. (Orgs.). Turismo de base comunitária: diversidade de olhares experiências brasileiras (p. 86). Rio de Janeiro: Letra e Imagem.

Cassio, J.C., Ferreira, D.L., Rodrigues, E.M. \& Santos, M.J.S. (2019). A culinária do Quilombo do Saco das Almas: perdas e danos do patrimônio cultural quilombola (p. 5). Revista de Estudos Africanos e Afro-Brasileiros, São Luís (3)

Clauzet, M., Ramires, M. \& Begossi, A. (2005). Pesca Artesanal e conhecimento local de duas populações caiçaras (Enseada do Mar Virado e Barra Una) no litoral de São Paulo (p. 2). MultiCiência: A linguagem da Ciência. São Paulo (4).

Da Rocha, J. (2017). Modos de vida, sistemas alimentares e transformaçôes: os caiçaras de Barbados, Paraná, Brasil (p. 46). Dissertação (Mestrado em Nutrição). Florianópolis: Universidade Federal de Santa Catarina.

Denardin, V.F., Lautert, L.F., Hernandes, C.C., Ribas, C.P., Piccin, H.H. \& Komarchescki, R. (2009). Casas defarinha no litoral do Paraná: Realidade e desafios. XIII Congresso Brasileiro de Mandioca, Botucatu.

Everett, S. \& Aitchison, C. The role of food tourism in sustaining regional identity: a case study of Cornwall, South West England. Journal of Sustainable Tourism. 2008;16(2):150-167

Ferreira, M.V. \& Jankowski, M. (2009). Cozinha caiçara: encontro de histórias e ambientes (p. 10). São Paulo: Editora Terceiro Nome.

Gândara,J.M.G; Gimenes, M.H.S.G;. Mascarenhas, R. Reflexóes sobre o turismo gastronômico na perspectiva da sociedade dos sonhos. In: PANOSSO NETTO, Alexandre; ANSARAH, Marília Gomes dos Reis. (org). Segmentação do mercado turístico: estudos, produtos e perspectivas. São Paulo: Manole, 2009, p. 179-194.

Gimenes-Minasse, M.H.S. (2013). Cozinhando a tradição: festa, cultura, história e turismo no litoral paraense. Curitiba: Editora UFPR.

Instituto do Patrimônio Histórico e Artístico Nacional [IPHAN] (2005). Ofício das Baianas de Acarajé. Recuperado em 02 maio, 2020, de: http://www.ipatrimonio.org/bahia-oficio-das-baianas-de-acaraje/\#!/ map $=38329 \&$ loc $=-12.924130999999997,-38.50844500000001,17$ 
Lobato, F.H.S., Aires, J.C.A. \& Ravena-Cañete, V. (2019). Belém, cidade criativa da gastronomia: uma Amazônia de sabores e de experiências turísticas. In: Lavandoski, J., Brambilla, A. \& Vanzella, E. (Orgs.). Alimentação e cultura: Alimentação e Turismo: criatividade, experiência e patrimônio cultural. João Pessoa: Editora do CCTA.

Martins, P., Frigo, S., Moscal, J., Zucon, O. \& Pinheiro, A. (2012). A pesca da tainha na Ilha do Mel: territorialidades, sociabilidades e técnicas. Curitiba: IPHAN

Martins, U. \& Costa, C. (2019). O Turismo Gastronômico como um fator dinamizador das culturas locais e das economias dos destinos: o caso do centro das tapioqueiras em Fortaleza. In: Lavandoski, J., Brambilla, A. \& Vanzella, E. (Orgs.). Alimentação e cultura: Alimentação e Turismo: criatividade, experiência epatrimônio cultural. João Pessoa: Editora do CCTA.

Mendonça, T.C.; Irving, M.A. Turismo de base comunitária: a participação como prática no desenvolvimento de projetos turístico no Brasil - Prainha Do Canto Verde, Beberibe (CE). Caderno Virtual de Turismo, v. 4, n. 4, p. 12-22, 2004.

Mendonça, J.T., Lucena, A.C.M., Muehlmann, L.D. \& Medeiros, R.P. (2017). Socioeconomia da pesca no litoral do estado do Paraná (Brasil) no período de 2005 a 2015. Desenvolvimento e Meio Ambiente, Curitiba, (41).

Montanari, M. (2008). Comida como cultura (p. 189). São Paulo: Editora Senac São Paulo.

Neves, C.S.B., Carvalho, I.S., Castro, E.S., Teixeira-Junior, D., Faias, V. \& Gomes, E.L. (2019). O conceito de encontrabilidade turística aplicado ao destino de Foz do Iguaçu (p. 45). Gomes, G.A.T. (Org.). Turismo, Sustentabilidade e Hospitalidade, (2). Ponta Grossa: Atena Editora. DOI: 10.22533/at.ed.730190209

Rede Anfitriōes do Litoral do Paraná - Turismo de Base Comunitária (2020). Recuperado em 02 maio, 2020, de Facebook Analytics: https://www.facebook.com/facebookanalytics/

Santos, V.F.N. \& Pascoal, G.B. (2013). Aspectos gerais da cultura alimentar paraense. Revista da Associação Brasileira de Nutrição, São Paulo, 5(1)

Slow Food Brasil (2007). O movimento. Recuperado em 02 maio, 2020, de: http:/www.slowfoodbrasil.com/ slowfood/o-movimento

Souza, F. (2020). Marketing Para o Turismo de Base Comunitária - O caso da Rede de Anfitriões do Litoral do Paraná. Monografia (Tecnologia em Gestão de Turismo). Matinhos: Universidade Federal do Paraná.

Yin, R.K. (1989). Case Study Research - Design and Methods (p. 19). Sage Publications Inc., USA.

\section{Notas}

[1] Conforme explicam (Santos \& Pascoal, 2013), cultura alimentar é um sistema simbólico em que cada sociedade estabelece um conjunto de práticas alimentares diretamente influenciadas por fatores históricos, ambientais e regionais. A culinária, pode ser compreendida como "ciência ou arte de elaboração dos alimentos através de técnicas, elementos e artefatos que trazem o conhecimento adquirido no tempo", conforme explicam (Brussio, Ferreira, Rodrigues \& Santos, 2019, p. 5).

[2] A exemplo desse processo de valorização do patrimônio associado à cultura alimentar, destaca-se o caso do tombamento do Ofício das Baianas de Acarajé, realizado pelo Instituto do Patrimônio Histórico e Artístico Nacional (IPHAN, 2020); a atribuição a determinadas localidades de título como "Cidade Unesco da Gastronomia", tais como Florianópolis (SC), Belém (PA) e Paraty (RJ).

[3] Assunto: Provar culinária local e aprender sobre a cultura alimentar. O respondente teria a opção de assinalar uma das seguintes opções: Muito interesse. Interesse médio. Pouco interesse. Nenhum interesse. Não sei.

[4] São apresentadas as seguintes opções de resposta, com possibilidade de assinalar mais de uma: Comer em casa de morador e provar culinária local. Comer em restaurante na comunidade e provar culinária local. Comer em restaurante ou casa de morador, com adaptaçóes da culinária local. Comer em restaurantes que não são da comunidade, mas que oferecem diversos tipos de culinária. Levar minha comida para cozinhar. Outros. 